\title{
From Tale to Tail: Unwinding the Twisted Life Story of PIG 05049 A Conversation with Christien Meindertsma
}

\author{
Maarten Vanden Eynde
}

Keywords: animal welfare, bio-industry, pigs, globalisation, food chain, design journalism, product design, memory, remembering

\begin{abstract}
Pig 05049 is a book and research project by Dutch designer Christien Meindertsma that chronicles the many consumer products that were made from a pig called 05049. The book offers an insightful look into how this one animal, a single source, provides raw material for a vast number of everyday objects. Meindertsma's clinical presentation of each laboriously researched object, page by page, organised by body part, follows the progress of the dissection of Pig 05049 and the subsequent use of each part. Some products, she found, are expected and familiar, whilst other diverge dramatically: ammunition, medicine, photo paper, cigarettes, conditioner, and bio diesel. PIG 05049 is currently in its 5th edition. The book won the Dutch Design Award in 2008 and the Index award in 2009 in the category Play. The article is a lightly edited transcript of a conversation between Commodity Frontiers editor, Maarten Vanden Eynde and Christien Meinderstma in September 2021.
\end{abstract}

\section{PIG 05049}

1:1 
Maarten Vanden Eynde: Thank you very much Christine for giving me your time to participate in this conversation. We are mainly going to talk about PIG, a project you produced already in 2007. At the time of the release of your publication I was still living in the Netherlands, and I remember reading in the newspaper that there were more pigs living in the Netherlands than people. I remember being very surprised about this but in retrospect it's strange because why wouldn't there be more pigs? Does it have something to do with the human tendency to put ourselves on top and this human arrogance to call ourselves homo sapiens sapiens, the double wise man? We named an entire geologic era, the Anthropocene, to human presence on earth, so maybe it has to do with that, but otherwise I think most animals are out numbering humans. In total there are at least 100 times more pigs than humans on the planet. So, I was just wondering if it has something to do with human nature that we want to dominate other species.

Christien Meindertsma: Yes, I understand your reasoning, but I think in this context for me personally it is a little bit different. The reason I find it odd is that we never see them even though they out number us. That is what is strange, that there are so many pigs and a very big industry, but they are invisible. Also, the massive number of pigs is not a wild representation of the species, but reflects those being kept as a product even though they are very close to humans and very intelligent. For example, the heart valve of a pig you can use as your own valve. They are raised in such closed systems and the only time you see a pig is when they are on a truck. Or at least the only time I see those pigs is when they are on their way to the slaughterhouse and you see their ears sticking out whilst you drive on the highway. It's so sad because it is their only time outside. So personally, I think that is what is very strange. The idea that you speak about placing ourselves on top of the ladder is not to do with the numbers of the pig but more for the fact that we think we can dominate them as if they are products and this is such a strange normality that we decided on in society. Of course, there are people arguing against this, vegetarians, and vegans, but most people are caught up in this chain system and conform to this as normality, when it is completely anything but normal.

MVE: I totally agree, and then you would expect that because we know about this that when the pig is made visible again through the likes of your work and animal rights activist who visualise these conditions that the animal endures that this would change our behaviour, but it seems we remain uncaring. It's like the blood minerals of which we all know now that they are part of our smartphones, but that doesn't change our behaviour to technology. Similarly, with fossil fuels we know that it causes global warming, but we continue to drive cars and fly planes. What creates this numbness that although we know that we are mistreating animals and effecting our planet, why can't we make this shift towards change?

CM: I think about this a lot, I think it depends a little bit on the subject. I do eat meat but very little, I am not against eating animals. I think if we consume a small quantity of meat, pay a fair price, along with treating the animal well it could be possible. Yeah, I do drive a car, but I only fly when it is really necessary for work and that means I haven't been on a plane in two years which I think is great. These are personally easy things for me to go without because I don't care for flying and if there was no meat, I would be ok without it. But for instance my car is quite important for me as it enables me to work on a personal level with a lot of people because I can visit them easily as they are often in complicated remote locations. So being without a car would hurt. I think everyone has their own personal relationship to processes that they can't be without and methods they can let go of. But then with the Corona Virus I find it so interesting to think about Schiphol airport during these last few years. Whenever I was there I though about how crazy it was, all these people that are there all the time flying. But now people are not there anymore, and you see that it is possible to not fly. What people missed the most was job availability and not seeing others, but not this crazy flying that we used to do. So, I think that's an interesting thought that a virus can completely and so quickly change our behaviour in a way that we never thought was possible. 


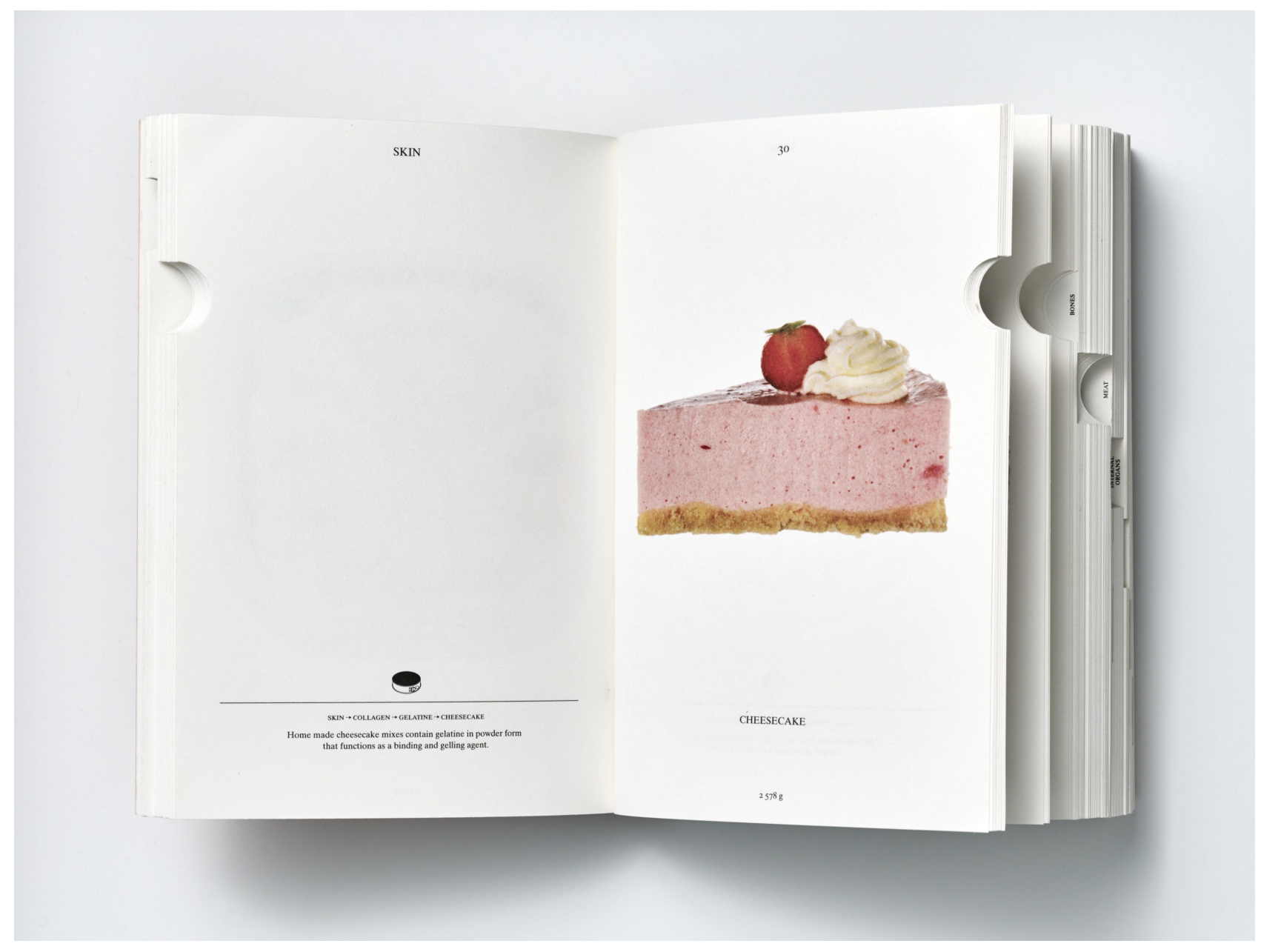

MVE: This was however a forced change in our behaviour. We didn't decide ourselves, knowing the implications of flying, that we should start to fly less. This virus came in and completely created a wall in front of us, showing that we couldn't continue.

CM: Yes, it shows that we can make enormous shifts with lots of people that we never thought were possible. In this case I think it could be super inspiring if we all decided together to eat meat once a week and we could collectively make the change. It would be so easy and have the results that we want.

MVE: So why can't we or why don't we? We know that this would be one of the easiest solutions for a lot of problems related to the meat industry.

CM: It's clear that it is a difficult question. What people say in surveys is not corresponding with the decisions that people make in the store.
MVE: Did it change for you? It's been almost fifteen years after the book, did this change your behaviour towards meat, and also towards wanting to know what is inside any product? Are you more conscious of ingredients and where they come from?

CM: Yes definitively, all my work is about that. In my daily life I'm a normal person with a family. Before I had children it was much easier to not shop at a store or ignore things. Now, with children, when you decide that you don't want to have a large mountain of plastic in the house it not that easy anymore. It just kind of happens. You are a part of the fabrication of daily life, and I would love to be more meticulous about it, but then I would need to work less because it's a serious task if you want to get away from the system of normal shopping. You have to make a serious lifestyle twist to change that.

But in my work life it is different. After the pig book I was quite sad about this pig story and so I decided to do a similar project but then with a material that I wanted to support instead of move against and so I made a 


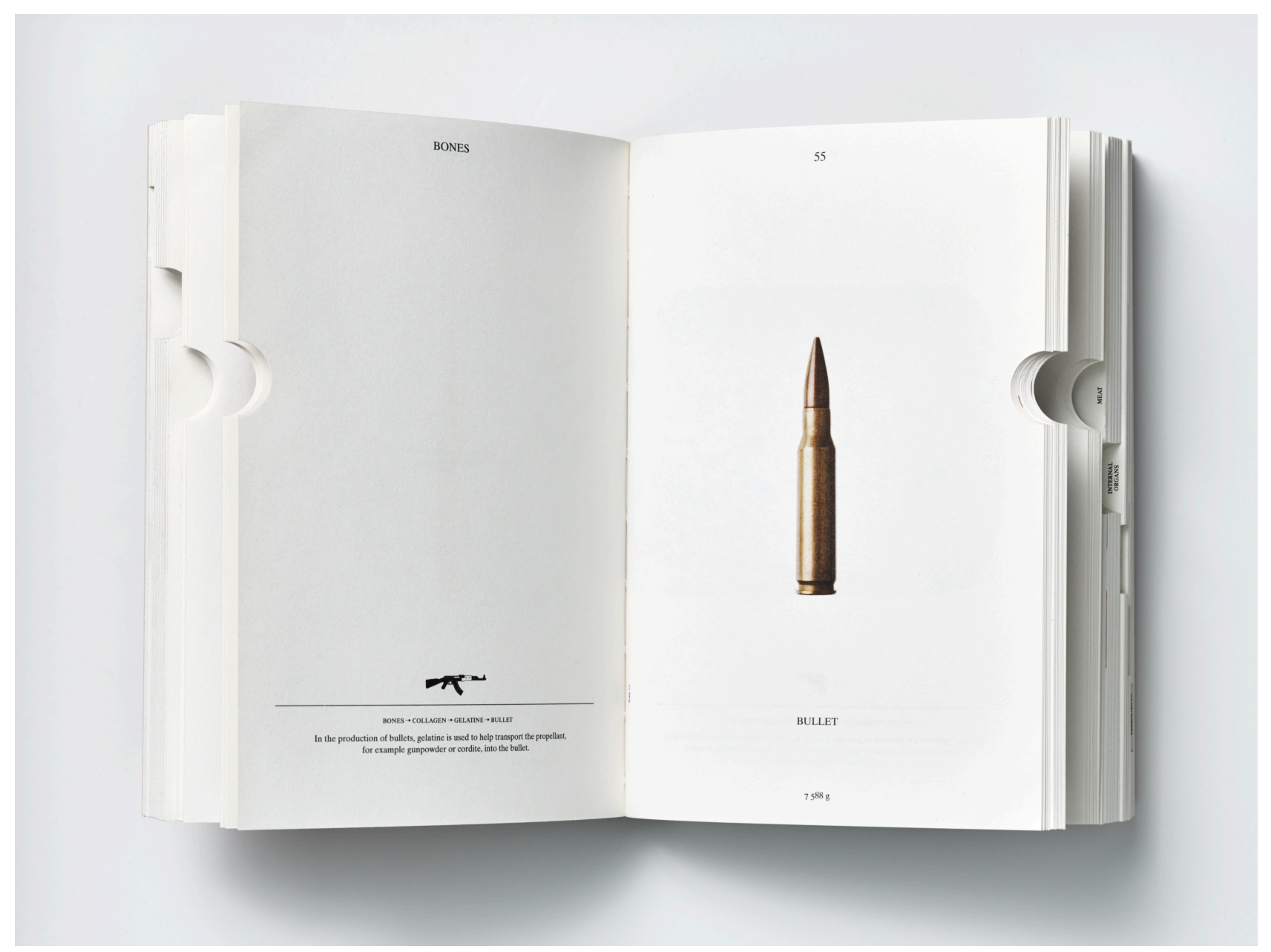

project with flax, the crop linen is made with mainly in Belgium and the Netherlands and that was very nice. It was a similar project but moved in another direction. Linen and flax are really a topic and material that people are choosing to work with and it's great to see. I am diving deeper into these sorts of elements, so it is similar to the pig book but now more towards the general system, now I am more interested to explore the longer chain of production. To see how a product changes from one thing to another and how this cycle works. I think the pig book is very much a part of my way of working but I don't really enjoy repeating myself so I wouldn't want to make a similar project about another animal, like a chicken.

MVE: I was thinking about whether a pig in that sense is more special or more used in different ways than a chicken for instance. Is it something particular about the pig that means there are so many possibilities of pig products? Or could you do the same thing with a chicken?
CM: Yes, you could. The first idea was to follow a cow but then with some logical reasoning along with the advice from a woman working in the meat industry, we concluded working with the pig as the subject would allow for a broader product range. Cows are used less as they suffered from the mad cows disease at that time, so the gelatine from cows was not used, therefore influencing fewer products. I thought the subject of a pig was interesting because you rarely see a pig in the landscape, but you are often able to see the cuddly looking cow in the field. Pigs are also very unloved, there is a culture that thinks they are a very unclean animal. Also, pigs are really close to humans, so there are a lot of reasons why they are interesting. I think a chicken would probably have less uses but would be super interesting as well. I would love to do a project around chickens but then I wouldn't make a book. It would be a different kind of outcome.

MVE: There are many more chickens than pigs (250 billion chickens worldwide) making chicken bones one of the possible leftovers to serve as a geologic marker that marks a 
transition between the Holocene into the Anthropocene. I found it shocking that they are so present all around the world that they will remain in the geological layer that we are constructing. But the other thing that I found very interesting is that pigs are so much closer to humans than cows or chickens. Now you already mentioned the heart valve and what I also understood is that scientists breed organs in pigs that can then be used for human transplants because they are so close to us. So, it is again another kind of astonishment, why don't we treat them better because they are so closely connected to us and indeed super smart? And recently there was the victorious Urgenda lawcase, the first time a government (The Netherlands) was held accountable for a lack of action against climate change. Something had to be done. There were many different options on how to immediately lower methane and nitrogen output and the first idea was to look at animals, and have less of them. However, the protest against this was so severe that in the end the Dutch government opted for a construction stop of buildings and they lowered the maximum speed on the highways to 100 just to make sure they could keep the same number of animals. So I wondered how they can prefer the option of reducing buildings and driving speed instead of having less animals or better conditions for them to live in. It seems so strange. When confronted with the opportunity to do something about the number and quality of livestock, we don't.

CM: One of the things I find interesting is that a lot of farmers feel that their country is not proud of them, so they have these stickers that say 'Trots of de Boer' (Proud of the Farmer) and whenever I see it I think this is very sad that they have these stickers. They need to almost shout at us to be proud of them because they are making our food. As a general reflection we aren't aware that we are paying too little money for the work that the farmers are doing, and we are defiantly paying a lot less than we were paying fifty years ago. On the other hand, they are also caught in a system that is so efficient they must continue to make these large productions to survive and thus become hostage in this system. I think every farmer would love to produce less for more money, but they somehow don't have the power to tell the system to be proud of them and that the money isn't the main issue. Even though it should be about the money because we should be paying more. This is a very interesting scenario in a conversation that we are not having together as a society.

MVE: Maybe that has something to do with globalisation because we used to pay more as the accessibility was less. It was more difficult to have pigs come from China which is where most pigs are now coming from. In order for local farmers to be competitive the government is subsidising farms to a level that is also not sustainable because it is then also too expensive.

CM: We are all caught in this complicated web where the rules of the game are changed because it is a global game and there are subsidies. This was why I tried to make the book as neutral as possible in terms of its opinion. If you choose sides within the layers of the story you also flatten the story. Of course, I am not always agreeing on how people interpret the book because it can be read in many different ways. One perspective could be that its positive that the pig is used for many different products, or you can think that it is horrible that the pig is in all these products that we use. Everyone who makes a different product in the book has a different story and I think looking back I am glad that it is as neutral as possible because I didn't want to condense a story that has so many perspectives and angels to it.

MVE: In that sense it is generous to leave it up to the reader to draw their own conclusion whether the use of a pig for a product is ethically, morally good, or not. I saw the book as a kind of monument, describing in a very neutral way what is made from the pig, a monument for the both the pig and strangely enough also the humans because we managed to make all this products. It made me think that we are successfully using every part of a pig which is also something we have always done as humans, to use an animal to its fullest capacity. We haven't changed much in how we deal with an animal so it has exactly this double feeling of goodness that we use every part of the animal but then on the other hand it is really cruel. A nice thing is that it also makes the same analogy as the book does: the pig is also shouting "be proud of me," look at what I am allowing you to make from me. 
Perhaps in that sense your book is the bumper sticker of the pig saying "be proud of me."

CM: This is why I find the farmers sticker 'Proud of the Farmer' conceptually so interesting. Someone is saying: be proud of me! It could almost take the form of a one sentence play: be proud of me for what I am doing. Personally, I think yes, I am very proud of you farmers but are they proud of the person who makes their clothes or any of the other products you may own? Farmers are equally caught up in this commodity system and there is this same level of questioning the amount of respect we have for workers. Can a farmer also be proud of the person who comes to deliver a cardboard package who is equally not paid in a fair way or who doesn't have fixed working hours? It is through this 'Proud of the Farmer' sticker that I have all these thoughts. Ok, we should be proud of you for making the food but are we equally as proud of the underpaid delivery driver? It reflects on a much larger problem around products and production and what we pay for them. I understand them but they are as guilty as we are with the other professions that work in production which in turn makes it so difficult to solve. If it was easy to solve for the farmer, the model could be translated to other professions where products are produced. There are farmers in Holland, many people who are trying to change their way of farming, many people who are willing and enthusiastic to have farms that are more circular where all the crops and animals are in a balanced system the way it should be. But they are confronted with the issue that banks don't want to lend money for these alternative systems. So even when you are a farmer, and you want to try and make a change it is really difficult.

MVE: Totally true. I remember being an early user of the Triodos Bank in the Netherlands, but still today in other countries like Belgium, Triodos exists only as a saving bank. The other banks won't allow for Triodos to use their cash machines and act on the same level as them because of the competition. As soon as you want to change something in the system, it fights back because ultimately it doesn't want to change.
CM: This is what makes it so difficult to initiate the change we were talking about in the beginning. But I don't want to be super negative about it because we can make really big changes. I am now working on a project around wool. Nearly all of it is being thrown away. There are companies that make synthetic insulation materials and they are vilifying the sheep, addressing them as being a very polluting animal. But the sheep is assisting in another way, by grazing the land. This lack of transparency of the true costs and benefits is used by opposing companies to only read into the calculations that they want to use for their argument. It is in the calculating system where this missinformation takes place. And the same with our farmers, they are all the time fighting with ministers over all these kinds of calculations that are bigger than we can understand which makes it then difficult to change.

MVE: So is that a project you are currently working on?

CM: Yes I returned to wool because I graduated with One Sheep Sweater eighteen years ago. It was always my dream to make an industrial or semi-industrial product from local sheep. Wool is deemed worthless and now eighteen years later the wool is still worthless, but the spirit of the times have changed and there are many people who are willing to invest on all different levels to think about ways not to throw away the sheep's wool. The city of Rotterdam has given me six thousand kilos of wool from the "Rotterdam flock of sheep' that is grazing the city.

MVE: I didn't even know it existed, the 'Rotterdam flock' sounds great.

CM: Yes, it really is. When you drive over the Van Brienenoord Bridge of Rotterdam you can see the sheep standing there on the dike. The wool from these sheep was always thrown away and the shepherd decided to act and asked the city council if they had a plan to avoid throwing away this wool. A lot of people were asked if you were given this wool what would you do. I presented a plan and they said you can have it, go for it. It has now been one year since that point and the wool is being sent off to become all different types of sample products. It has been washed, combed, cleaned and separated into different 


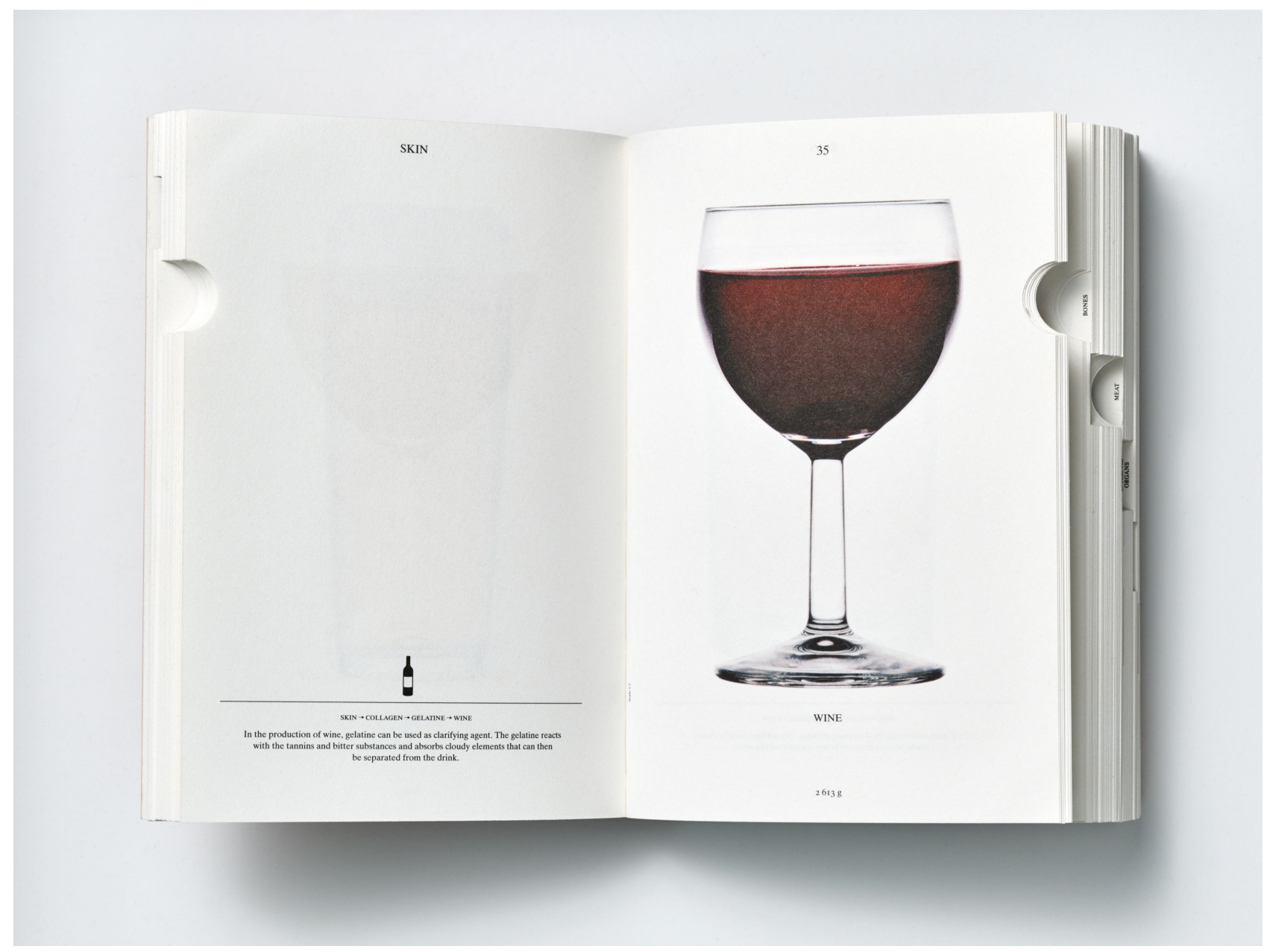

kinds of qualities. The highest quality will be donegal tweed which is the most beautiful tweed there is. The lowest quality will have plants growing on it. There will be uses for insulation, it will be a whole range of beautiful things that can be made from the sheep's fleece. It really feels like the crown on my work to receive this assignment. It is such a nice statement to make, and it is so nice not to be bound to the economics of it. We will calculate the prices of course, but it is not about that. It is about showing possibilities and then choosing one that can hopefully overrule the current system where the wool is just burnt. We need to invent a way to use this wool better than to burn it because it is not just the Rotterdam sheep's wool that is being burnt. There is so much wool being discarded in this way, it is so sad. The fact that it is still allowed for high class brands like Hermes and Channel to continue to burn their products so that the market value doesn't devalue, now that should be a crime. To shred a new product just because otherwise the market value goes down is just so disrespectful.
MVE: Oh yeah yeah yeah, and it reminds me of inbuilt obsolescence, something that started a while ago to make a product break down at a certain moment. I think that too should be a crime. But it's nice that you somehow shifted after the book with pigs to turn toward something positive showing good things you can make from something not being used, compared with looking at bad things that are being produced from something. It's as if you made a switch to positivity and change from stagnation and resignation.

CM: Yeah, it is also like the pig book in leaning towards journalism, design journalism, which is a nice way to research because I think you find out different things. For example, with the flax project because I had ten thousand kilos of flax, you find out very different things than if you just did research in language form. You see a totally different world. Then with the pig book it stayed very much research in language, and I think as a designer that seems too easy to describe something but not give a solution in your own practice. I am product designer, so to just 


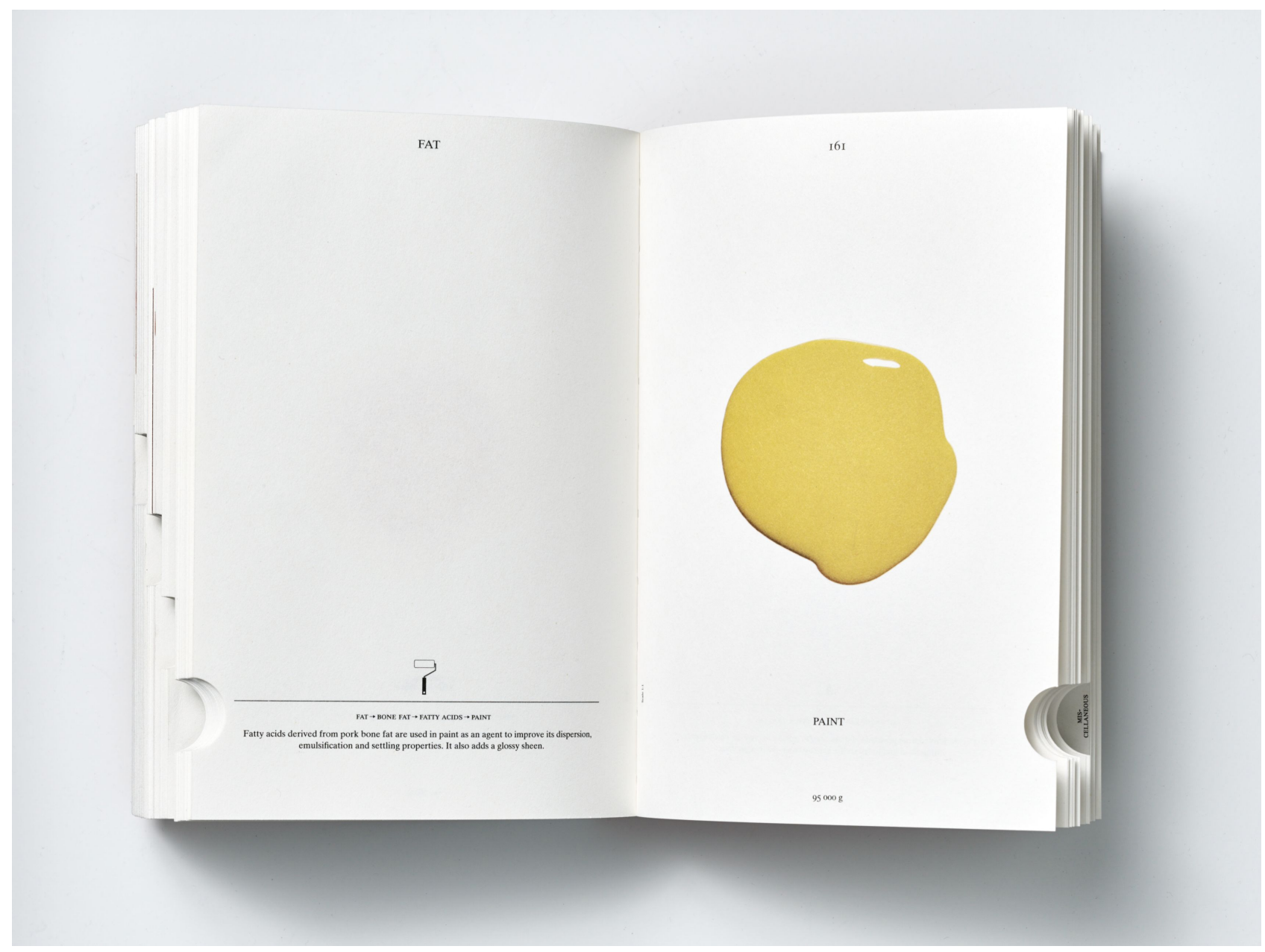

point at another product that I think isn't good enough is not enough. I should be the person trying to improve it, not just point at the person who I think is doing it wrong. So that is the feeling I had after the book, that even on a small scale, I would try to add something positive in a real situation, like baking a really nice bread.

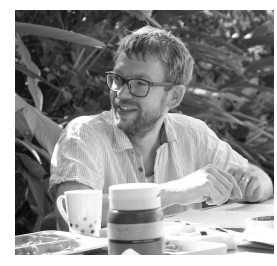

Maarten Vanden Eynde is a visual artist and co-founder of the artist run initiative Enough Room for Space. His practice is embedded in long term research projects that focus on numerous subjects of social and political relevance such as postindustrialism, capitalism and ecology. Since 2020 he is a $\mathrm{PhD}$ candidate at the UiB / University of Bergen in Norway focusing on material traces that could represent human presence on Earth in the far future.

*All photos provided by Christien Meindertsma.

\section{Correspondence:}

Maarten Vanden Eynde, maartenvandeneynde@protonmail.com.

\section{Cite this article:}

Vanden Eynde, M. (2021). "From Tale to Tail: Unwinding the Twisted Life Story of PIG 05049, A Conversation with Christien Meindertsma." Commodity Frontiers 3: 29-36. doi: 10.18174/ cf.2021a18160.

Commodity Frontiers is an open-access journal edited by the CFI Editorial Board, Mindi Schneider, senior editor. Read it online at Commodity Frontiers, or our website, commodityfrontiers.com.

This work is licensed under a Creative Commons Attribution-NonCommercial 4.0 International License 